\title{
Multi-objective performance optimization of ammonia decomposition thermal storage reactor
}

\author{
XIE Tianchao $^{1 \mathrm{a}}$, XIA Shaojun ${ }^{1 \mathrm{~b}}$, WANG Chao ${ }^{1}$ \\ ${ }^{1}$ College of Power Engineering, Naval University of Engineering, 430033 Wuhan, Hubei, China
}

\begin{abstract}
Heat storage technology plays an essential role in the stable operation of solar thermal power generation. In this paper, a one-dimensional model of a tubular filled bed heat absorption reactor for ammonia decomposition is established by applying finite time thermodynamics. Taking the inlet temperature, the outside diameter and the length of the reactor as optimization variables, the multi-objective particle swarm optimization is used to perform multi-objective optimization considering the maximum heat absorption rate and the minimum total entropy generation rate, and the Pareto Fronts are determined under different reactor outer wall temperatures. Finally, three optimized reactors' design parameters and performance indicators are obtained by LINMAP, TOPSIS and Shannon Entropy decision methods, and the cross-sectional comparison of the optimal reactors at different outer wall temperatures. Compared to the reference reactor, the three optimized reactors improve heat absorption rate by $58 \%-143 \%$, while the total entropy generate rate is reduced by $26.4 \%-38.8 \%$. The obtained results have some guidance for optimal designs of ammonia decomposition reactor in real engineering.
\end{abstract}

\section{Introduction}

In order to achieve the strategic goal of reaching the carbon peak by 2030 and becoming carbon neutral by 2060, China will intensify efforts to promote the transformation of the energy industry during the 14th Five-Year Plan period. Solar energy will be exploited to new heights.

Thermal storage systems are essential for the stable operation of solar thermal power generation. And amino thermochemical heat storage is a promising solar thermal storage technology. ANU's Luzzi [1] developed the world's first solar-powered experimental plant that used ammonia for thermal storage, and achieved 24-hour stable power generation.

In the simulation and analysis of ammonia decomposition reactor performance, Deng et al. [2] established a three-dimensional physical model of a tubular packed bed reactor and found that smaller catalyst particle sizes were effective in enhancing ammonia decomposition rates and reducing maximum wall temperatures. Wang et al [3] designed a self-heating shell and tube reactor with the hydrogen combustion catalyst attached to the inner tube, which increases the ammonia decomposition rate considerably by consuming hydrogen. Besides numerical analyses, Li et al. [4] used COMSOL software to carry out simulation modeling for the ammonia decomposition reactor. Membrane reactors have attracted the attention of researchers due to their ability to

\footnotetext{
a archiboldxie@163.com

*Corresponding author: ${ }^{\text {* }}$ shaojunxia_2021@163.com, 398843013@qq.com
}

filter out hydrogen to drive the ammonia decomposition reaction towards a positive reaction. Abashar et al. [5] developed a mathematical model of a small-scale membrane reactor and found that improved inlet ammonia feeding could significantly reduce the reactor length. Li and Liu [6] showed that a high performance new structure composite palladium membrane reactor can achieve complete decomposition of ammonia at $673 \mathrm{~K}$.

Since its inception in the mid-1970s [7], Finite Time Thermodynamics (FTT) has made important progresses in both physics and engineering. In the FTT studies of ammonia decomposition reactors, $\mathrm{Hu}$ et al. [8] developed a one-dimensional ammonia decomposition reactor model and determined the reactor diameter and length for the highest ammonia decomposition rate. Badescu et al. [9] obtained the optimum distribution of temperature along the pipe wall, the pipe diameter and the catalyst particle size distribution with the objectives of maximizing the ammonia decomposition rate and minimizing the heat flux under a predetermined ammonia decomposition rate.

As can be seen above, the former analysis and optimisation of ammonia decomposition reactors focused mainly on the ammonia decomposition to hydrogen scenario and was usually carried out with the single objective of maximising the ammonia decomposition rate or minimising the heat flux etc. However, as a heat storage reactor, the important performance indicator of maximum heat absorption was not fully considered. Besides, the multi-objective optimisation of minimum entropy generation rate and maximum heat absorption was also lacking. Therefore, 
this paper will further develop a multi-objective optimisation for minimising the total entropy yield and maximising the heat absorption rate for the practical application scenarios of ammonia decomposition heat storage reactors with finite rate heat transfer and chemical reaction.

\section{Materials and Methods}

A schematic diagram of the reactor model is shown in Figure 1. The ammonia gas flows axially, absorbs heat from the wall of the tube and undergoes a decomposition reaction.

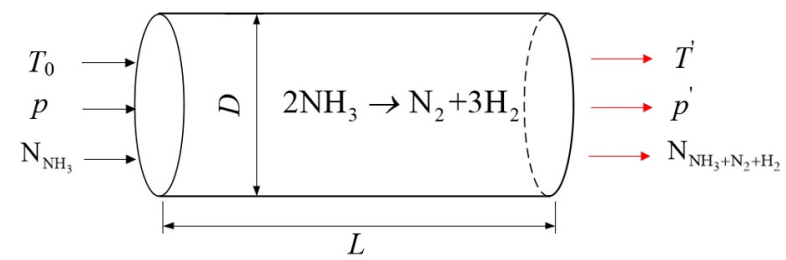

Figure 1 Ammonia decomposition reactor model

Table 1 Reference reactor model parameters [8,9]

\begin{tabular}{|c|c|c|}
\hline Physical quantities & Symbols & Value \\
\hline $\begin{array}{c}\text { Reactor outer } \\
\text { diameter }\end{array}$ & $D_{\mathrm{o}}$ & $16 \mathrm{~mm}$ \\
\hline $\begin{array}{c}\text { Reactor wall } \\
\text { thickness }\end{array}$ & $\delta_{\mathrm{w}}$ & $1 \mathrm{~mm}$ \\
\hline Reactor length & $L$ & $3 \mathrm{~m}$ \\
\hline $\begin{array}{l}\text { Reactor outer wall } \\
\text { temperature }\end{array}$ & $T_{\mathrm{w}}$ & $800 \mathrm{~K}$ \\
\hline $\begin{array}{l}\text { Reactor wall thermal } \\
\text { conductivity }\end{array}$ & $\lambda_{\mathrm{w}}$ & $100 \mathrm{~W} / \mathrm{m} \cdot \mathrm{K}$ \\
\hline $\begin{array}{c}\text { Reactor wall specific } \\
\text { heat capacity }\end{array}$ & $c_{\mathrm{W}}$ & $700 \mathrm{~J} / \mathrm{kg} \cdot \mathrm{K}$ \\
\hline Reactor wall density & $\rho_{\mathrm{w}}$ & $4000 \mathrm{~kg} / \mathrm{m}^{3}$ \\
\hline Catalyst density & $\rho_{\mathrm{c}}$ & $2355.2 \mathrm{~kg} \cdot \mathrm{m}^{-3}$ \\
\hline $\begin{array}{c}\text { Catalyst particle } \\
\text { diameter }\end{array}$ & $d_{\mathrm{p}}$ & $2.23 \mathrm{~mm}$ \\
\hline Catalyst porosity & $\varepsilon_{\mathrm{p}}$ & 0.59 \\
\hline $\begin{array}{c}\text { Catalyst thermal } \\
\text { conductivity }\end{array}$ & $\lambda_{\mathrm{c}}$ & $0.3489 \mathrm{~W} \cdot \mathrm{m}^{-1} \cdot \mathrm{K}^{-1}$ \\
\hline $\begin{array}{l}\text { Inlet ammonia molar } \\
\text { flow rate }\end{array}$ & $N_{\mathrm{NH}_{3}}$ & $0.025 \mathrm{~mol} / \mathrm{s}$ \\
\hline $\begin{array}{l}\text { Inlet hydrogen molar } \\
\text { flow rate }\end{array}$ & $N_{\mathrm{H}_{2}}$ & $0.001 \mathrm{~mol} / \mathrm{s}$ \\
\hline $\begin{array}{l}\text { Inlet nitrogen molar } \\
\text { flow rate } \\
\end{array}$ & $N_{\mathrm{N}_{2}}$ & $0.001 \mathrm{~mol} / \mathrm{s}$ \\
\hline Reaction pressure & $p$ & $10 \mathrm{MPa}$ \\
\hline Inlet gas temperature & $T_{0}$ & $350 \mathrm{~K}$ \\
\hline
\end{tabular}

With pressures up to $10 \mathrm{MPa}$ during the ammonia decomposition reaction, the ideal gas state equation does not hold on. Tian [10] combined the actual gas compression factor and a trial method to obtain a single constant actual gas equation of state, which was very fit for hydrogen, nitrogen and ammonia.

$$
\begin{aligned}
& V= \frac{n R T}{p}\left\{2-e^{\frac{p_{\mathrm{r}}}{T_{\mathrm{r}}}\left[\frac{T_{\mathrm{rit}}}{T}\left(\left(-\frac{T}{903.65}\right)^{227 .}-\left(\frac{T-T_{\mathrm{ri}}}{903.65}\right)^{2}\left(p_{\mathrm{r}}-T_{\mathrm{r}}\right)^{2}\right]\right.}\right\} \\
& p_{\mathrm{r}}=\frac{p_{\mathrm{cr}}}{p} \\
& T_{\mathrm{r}}=\frac{T_{\mathrm{cr}}}{T}
\end{aligned}
$$

where $p_{\mathrm{r}}$ is the reduced pressure, and $p_{\mathrm{cr}}$ is the critical pressure. $T_{\mathrm{r}}$ is the reduced temperature, and $T_{\mathrm{cr}}$ is the critical temperature. $T_{\text {tri }}$ is the three-phase point temperature in K. $c$ is a parameter related to the substance only and the corresponding values of $\mathrm{H}_{2}, \mathrm{~N}_{2}$ and $\mathrm{NH}_{3}$ are $0.28,0.415$ and 0.98 , respectively [10].

According to the first law of thermodynamics, the equation for energy conservation is:

$$
\frac{\mathrm{d} T}{\mathrm{~d} z}=\frac{\pi D_{\mathrm{i}} q-A_{c} \rho_{c}\left(1-\varepsilon_{p}\right) \sum_{j} \eta_{j} r_{j} \Delta_{\mathrm{r}} H_{j}}{\sum_{k} F_{k} C_{p, k}}
$$

where $A_{\mathrm{c}}$ is the cross-sectional area inside the reactor in $\mathrm{m}^{2} . \Delta_{\mathrm{r}} H_{j}$ is the enthalpy of reaction $j$ in $\mathrm{kJ} / \mathrm{mol} . \eta_{j}$ is the effective factor of internal diffusion. $r_{j}$ is the intrinsic reaction rate of reaction $j$ in $\mathrm{mol} / \mathrm{s} . C_{p, k}$ is the molar constant pressure heat capacity of the component $k . F_{k}$ is the molar flow rate of the component $k$ in mol/s. $q$ is the heat flow density in $\mathrm{W}$.

The Hicks pressure drop equation is used to describe the momentum conservation properties in the reactor, as follows:

$$
\frac{\mathrm{d} p}{\mathrm{~d} z}=-6.8 \frac{\left(1-\varepsilon_{\mathrm{p}}\right)^{1.2}}{\varepsilon_{\mathrm{p}}{ }^{3}} \operatorname{Re}^{-0.2} \frac{\rho_{\mathrm{m}} v_{\mathrm{m}}^{2}}{d_{\mathrm{p}}}
$$

where $\rho_{\mathrm{m}}$ is the density of the reaction mixture in $\mathrm{kg} / \mathrm{m}^{3} \cdot v_{\mathrm{m}}$ is the average flow rate of the reaction mixture in $\mathrm{m} / \mathrm{s}$.

The mass conservation equation can be expressed using the differential equation for the rate of conversion as follows.

$\frac{\mathrm{d} \xi_{j}}{\mathrm{~d} z}=\frac{A_{c} \rho_{c}}{F_{k, \text { in }}} \sum_{\mathrm{j}} \eta_{j} r_{j}$

Ammonia decomposition reactions obey the TemkinPyzhev reaction rate equation:

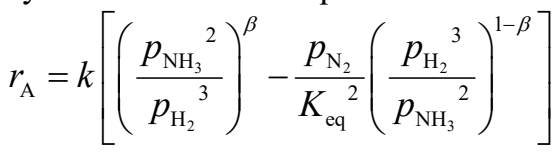

$k=k_{0} e^{-E_{a} / R T}$

where $r_{\mathrm{A}}$ is the kinetic rate of ammonia decomposition reaction in mol/s. $k$ is the reaction rate constant in $\mathrm{mol} /\left(\mathrm{s} \mathrm{bar}^{\beta}\right) . k_{0}$ is its correlation factor, taking the value of $13.51 \times 10^{6}\left[\mathrm{~mol} /\left(\mathrm{s} \mathrm{bar}^{\beta}\right)\right] . \beta$ is the dimensionless constant and takes the value of $0.166 . E_{\mathrm{a}}$ is the activation energy of the ammonia decomposition reaction, the value is $107.1 \mathrm{~kJ} / \mathrm{mol}$. $\mathrm{R}$ is the gas constant, and the corresponding value is $8.314 \mathrm{~kJ} /(\mathrm{mol} \cdot \mathrm{K}) . p_{i}$ are the sub-pressure of $\mathrm{H}_{2}, \mathrm{~N}_{2}$ and $\mathrm{NH}_{3}$. The chemical reaction equilibrium constant $K_{\mathrm{eq}}$ are read from the HSC software.

The thermal resistance of thermal conductivity from the outer to the inner wall of the reactor is: 
$R_{\mathrm{w}}=\frac{\ln D_{\mathrm{o}} / D_{\mathrm{i}}}{2 \pi \lambda_{\mathrm{w}} \Delta L}$

For convective heat transfer between the reactor walls and the reaction mixture, the $\mathrm{Nu}$ is calculated using the Gnielinski equation [11]:

$$
\mathrm{Nu}=\frac{\left(\frac{f}{8}\right)(\operatorname{Re}-1000) \operatorname{Pr}}{1+12.7 \sqrt{\frac{f}{8}}\left(\operatorname{Pr}^{\frac{2}{3}}-1\right)}\left[1+\left(\frac{d}{l}\right)^{\frac{2}{3}}\right]\left(\frac{T_{\mathrm{f}}}{T_{\mathrm{w}}}\right)^{0.45}
$$

the flow resistance coefficient $f$ is calculated using the Filonenko formula:

$$
f=\left(1.82 \log _{10} \operatorname{Re}-1.64\right)^{-2}
$$

and the Re is calculated by:

$$
\operatorname{Re}=0.354 \times \frac{Q_{\mathrm{m}}}{D_{\mathrm{i}} \mu}
$$

where $Q_{\mathrm{m}}$ is the mass flow rate of the gas mixture in $\mathrm{kg} / \mathrm{h}, D_{\mathrm{i}}$ is the inner diameter of the reactor in $\mathrm{mm}$, and $\mu$ is the kinetic viscosity of the gas in $\mathrm{Pa} \cdot \mathrm{s}$.

The total local entropy generation rate for finite temperature differential heat transfer, finite rate chemical reactions and finite differential pressure flow in the reactor is:

$$
\sigma=\pi \cdot d_{\mathrm{r}, \mathrm{in}} J_{\mathrm{q}} \cdot\left[\left(\frac{1}{T_{\mathrm{in}}}-\frac{1}{T_{\mathrm{w}}}\right)+\left(\frac{1}{T}-\frac{1}{T_{\mathrm{in}}}\right)\right]+A_{\mathrm{c}} \rho_{\mathrm{c}} r_{\mathrm{A}} \frac{\Delta G}{T}+A_{\mathrm{c}} c_{\mathrm{g}} \frac{1}{T} \frac{\mathrm{d} p}{\mathrm{~d} z}(
$$

The total entropy generation rate of the reactor is the integral of the total local entropy generation rate along the tube length.

$S G=\int_{0}^{L} \sigma \mathrm{d} z$

As mentioned earlier, this paper will apply a multiobjective particle swarm optimization to carry out a multiobjective optimization with the objective of maximizing the heat absorption rate and minimizing the total entropy generation rate of the reactor. The objective function of the optimization problem is:

$$
\min (-Q, S G)
$$

The constraints are:

$$
350 \mathrm{~K}<T_{0}<450 \mathrm{~K}
$$

$$
0.01 \mathrm{~m}<D_{o}<0.02 \mathrm{~m}
$$

$2 \mathrm{~m}<L<20 \mathrm{~m}$

\section{Results \& Discussion}

$650 \mathrm{~K}, 700 \mathrm{~K}, 750 \mathrm{~K}, 800 \mathrm{~K}, 850 \mathrm{~K}$ and $900 \mathrm{~K}$ are chosen as the outer wall temperature of the reactor, respectively, and 6 Pareto Fronts are obtained. Figure 2 shows the Pareto Front when the outer wall temperature of the reactor is 900K. As seen in Figure 2, the optimal frontier space can be divided into four quadrants using the reference reactor point as the origin. According to the physical significance of the coordinate axes, the optimal reactors distributed in the first quadrant have both higher total entropy generation rate and higher heat absorption rate compared to the reference reactor; the optimal reactors distributed in the third quadrant have both lower heat absorption rate and total entropy generation rate; the optimal reactors distributed in the fourth quadrant have higher heat absorption rate with lower total entropy generation rate.

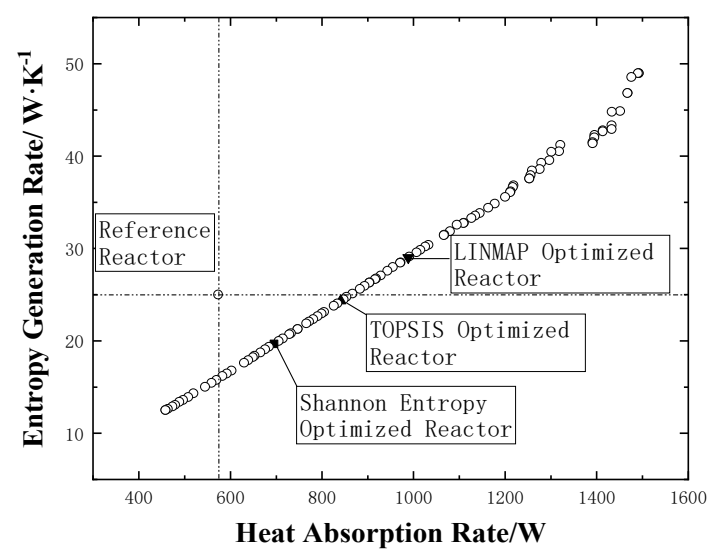

Figure 2 The Pareto Front with $900 \mathrm{~K}$ outer wall temperature

Three decision methods, TOPSIS, LINMAP and Shannon Entropy(SE) are further applied to 6 Pareto Fronts under different reactor outer wall temperatures, respectively, 18 optimal reactors' design parameters and performance indexes are obtained.

In order to determine better operating temperatures and to narrow the selection space of optimal reactors to guide engineering practice more precisely, optimal reactors at different temperatures are compared horizontally in Figure 3 to 5.

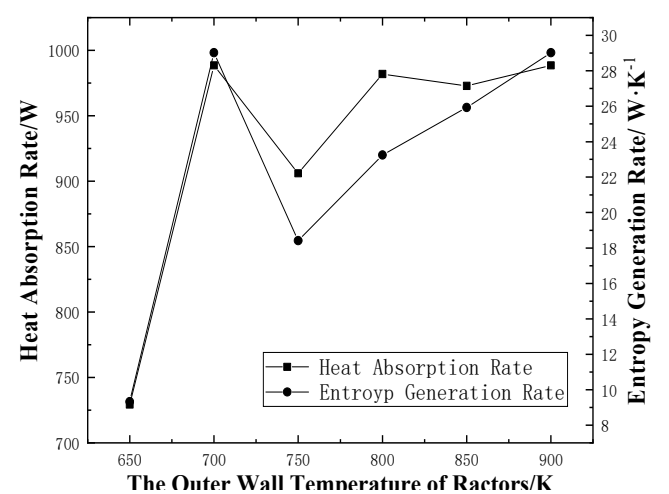

Figure 3 Performance indicators for LINMAP optimal reactors

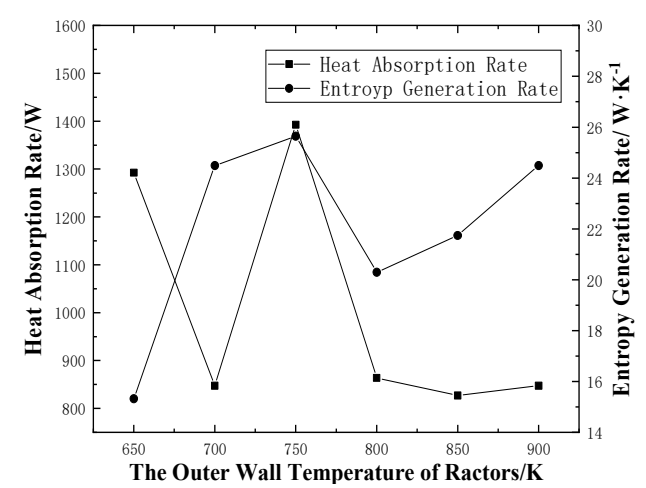

Figure 4 Performance indicators for TOPSIS optimal reactors 


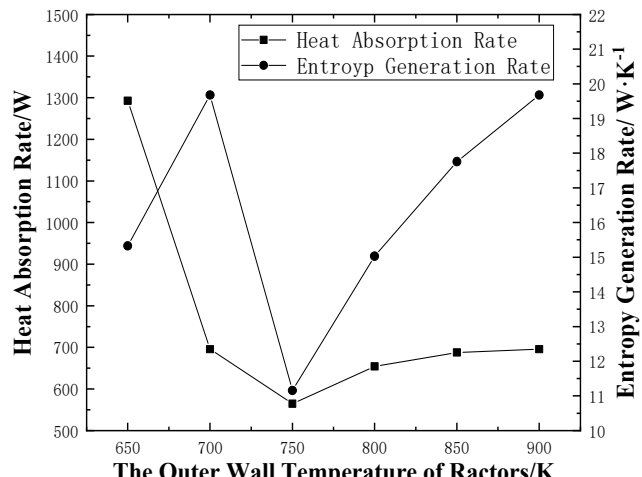

Figure 5 Performance indicators for SE optimal reactors

As seen in Figure 3, the entropy generation rate of the corresponding LINMAP optimum reactor decreases more significantly than the heat absorption rate as the temperature of the outer wall of the reactor increases from $700 \mathrm{~K}$ to $750 \mathrm{~K}$. Moreover, the heat absorption rate does not increase more significantly than the entropy generation rate all the way from $750 \mathrm{~K}$ to $900 \mathrm{~K}$. Therefore, the LINMAP optimum reactor at $750 \mathrm{~K}$ is a better choice. Similarly, the TOPSIS optimal reactors at $650 \mathrm{~K}$ and $750 \mathrm{~K}$, and the Shannon Entropy optimal reactor at $650 \mathrm{~K}$ are all preferable options(The Shannon Entropy optimal reactor and the TOPSIS optimal reactor are identical at $650 \mathrm{~K}$ ). The final three best choices are listed in Table 2.

Table 2 The parameters of three final choices

\begin{tabular}{|c|c|c|c|}
\hline Parameters & $\begin{array}{c}\text { Choice } \\
1\end{array}$ & $\begin{array}{c}\text { Choice } \\
2\end{array}$ & $\begin{array}{c}\text { Choice } \\
3\end{array}$ \\
\hline $\begin{array}{c}\text { Outer wall } \\
\text { temperature(K) }\end{array}$ & 750 & 650 & 750 \\
\hline Outer diameter(m) & 0.02 & 0.02 & 0.02 \\
\hline Length(m) & 5.7 & 20 & 9.5 \\
\hline Inlet temperature(K) & 427 & 449 & 389 \\
\hline Heat absorption rate(W) & 906.0 & 1292.5 & 1392.7 \\
\hline $\begin{array}{c}\text { Entropy generation } \\
\text { rate(W/K) }\end{array}$ & 18.4 & 15.3 & 25.6 \\
\hline
\end{tabular}

\section{Conclusions}

In this paper, finite time thermodynamics is applied to analyze the heat absorption decomposition process in a tubular packed-bed ammonia decomposition reactor under constant external wall conditions. The effects of three parameters, reactor inlet temperature, reactor outer diameter and length on the heat absorption rate and entropy generation rate of the reactor were analyzed. And the results show that:

(1) Within the given constraints, the multi-objective optimized reactors tend to have a bigger reactor diameter to effectively enhance the heat absorption rate.

(2) The comparison of multi-objective optimal reactors for different temperatures shows that the outer wall temperatures are not the higher the better, while $650 \mathrm{~K}$ and $750 \mathrm{~K}$ are two better choices.

(3) Through the comparison of 18 optimal reactors at different outer wall temperatures, three better choices were obtained. Compared to the reference reactor, the three optimal reactors improve heat absorption rate by $58 \%-143 \%$, while the total entropy generate rate is reduced by $26.4 \%-38.8 \%$.

\section{Acknowledgements}

This paper is one of the periodic achievements of the following foundation projects:

National Natural Science Foundation of China (NSFC) funded projects: No. 51976235; No. 51606218.

Hubei Natural Science Foundation funded project: 2018 CFB708.

\section{References}

1. Luzzi A. (1995) High temperature solar tests with $1 \mathrm{kWchem}$ ammonia reactor. J. Fuel \& Energy Abstracts, 36: 271.

2. Deng $\mathrm{Z} \mathrm{H}, \mathrm{Hu}$ T, Tian J M, et al. (2020) Performance of a novel single-tubular ammoniabased reactor driven by concentrated solar power. J. Solar Energy, 204: 696-707.

3. Wang Y F, Duang X Z, Wu Y, et al. (2015) Modeling and analysis of concentric self-thermal fixed-bed reactor for ammonia decomposition. J. CIESC Jorunal, 66: 3169-3176.

4. Li W, Chen W, Cheng J. (2017) Numerical simulation of heat storage process based on ammonia decomposition. J. Energy Research \& Utilization, 04: 40-42.

5. Abashar M. (2019) The impact of ammonia feed distribution on the performance of a fixed bed membrane reactor for ammonia decomposition to ultra-pure hydrogen. J. International Journal of Hydrogen Energy, 44: 82-90.

6. Li H, Liu L. (2020) A new palladium composite membrane with high performance was developed in Dalian Institute of Chemical Physics and applied in an ammonia decomposition membrane reactor. J. Membrane Science and Technology, 40: 170.

7. Andresen B, Berry R, Nitzan A, et al. (1977) Thermodynamics in finite time. I. The step-Carnot cycle. J. Physical Review, 15: 2086-2093.

8. Hu T, Wang Y. (2020) Effect of operating and geometrical parameters on Ammonia decomposition in a tubular reactor driven by concentrating solar power. J. Journal of Energy Engineering, 146: 4020018.

9. Badescu V. (2020) Optimal design and operation of ammonia decomposition reactors. J. International Journal of Energy Research, 44: 5360-5384.

10. Tian Z B. (1988) The monoconstant semiempirical equation of state of real gases. J. Journal of Xi'an Institute of Metallurgy and Construction Engineering, 01: 77-86. 
11. Tao W Q, Yang S M. (2006) Heat transfer (the fourth edition). High Education Press, Beijing. 